\title{
ROUTINE TESTING OF BITUMEN BINDERS
}

\author{
Michal HOLÝ1, ${ }^{1}$, Eva REMIŠOVÁ ${ }^{1}$ \\ ${ }^{1}$ Department of Highway Engineering, Faculty of Civil Engineering, University of Žilina, Univerzitná \\ 8215/1, 01026 Žilina, Slovakia. \\ corresponding author: michal.holy@fstav.uniza.sk
}

\section{Abstract}

The quality of bituminous binders used in the construction and maintenance of road surfaces is currently assessed by empirical testing based on obtaining one value for specific boundary conditions, which were designed about 100 years ago. Basic empirical tests include the softening point and penetration, but the practice shows that these tests appear to be inadequate. The evaluation of changes of bitumen properties during the production and paving process of bituminous mixture is also important. The paper points out how the "traditional" tests as softening point and penetration and viscosity are sufficient to evaluate properties of bitumen binders.
\end{abstract}

\section{Keywords:}

Bitumen binder; Viscosity; Softening point; Penetration.

\section{Introduction}

One of the basic conditions $[6,9]$ for the construction of a quality building work is the selection of suitable types of materials (e.g. coarse aggregate, filler, bitumen binder), their quality, and strict adherence to technological conditions during production respectively compaction of asphalt mixtures.

Currently, there are several manufacturers of bitumen worldwide and each of them uses their own technological processes for processing and newest technology and with their help ensure the required quality and application properties of the product. These properties are then verified by the prescribed tests which bitumen binder must satisfy and which are critical to the designation and definition of bitumen binders. Bitumen quality criteria are defined in European Product Standard and detailed in bitumen catalogue sheets valid for roads and highways in Slovakia. The datasheets determine the ways and use of bitumen binders for the production of mixtures for wearing, binder and base courses

When characterizing bitumen binders and determining their properties, we encounter variability of the results. Wide range of specified penetration values (between 10 and $50 \times 0.1 \mathrm{~mm}$ ) and softening point $\left(8^{\circ} \mathrm{C}\right)$ or with modified bitumen binders, determining only the lower limit causes that bitumen binders of the same grade (of the same kind) to have different properties. During processing of design of asphalt mix within type test is used a bitumen with certain penetration values and softening point e.g. at the lower edge within the allowed limit and asphalt mix is designed and set to certain parameters so that the requirements are met of KLAZ (Data sheets of bitumen binders) [10]. However, if asphalt is used in production which complies with specified grades of bitumen but values of penetration and softening point are at close to the upper limit, such an asphalt mixture no longer has to meet the required parameters, e.g. it will not have sufficient resistance to permanent deformation during the summer.

\section{Bitumen and quality assessment}

Bitumen as a hydrocarbon binder [8] is considered a relatively complex material whose properties are related to colloidal structure and chemical composition. There are different types of bitumen available with different properties, specifications, and uses based on requirements of consuming industry. The specification of bitumen also shows variation with the safety, solubility, physical properties, and the durability. Paving grade bitumens and polymer-modified bitumens are most commonly used. Polymer modified bitumen (PMB) is one of the specially designed and engineered bitumen grades that is used in making pavement, roads for heavy duty traffic, and home roofing solutions to withstand extreme weather conditions. PMB is normal bitumen with added 
polymer, which gives it extra strength, high cohesiveness and resistance to fatigue, stripping and deformations, making it a favourable material for structure of pavement. We can also characterize polymer modified bitumen as a type of bitumen obtained by modification of strength and rheological properties of penetration graded bitumen. In PMB, from 2 to $8 \%$ of polymer is added. As polymer can be either of plastomeric or elastomeric nature. These polymers ameliorate the strength and the viscoelastic properties of the bitumen. This is achieved by:

1. elastic response increase,

2. improvement in cohesive property,

3. improvement in fracture strength,

4. providing ductility.

Paving grade bitumens are characterised by their consistency at intermediate service temperature (determined by penetration test), consistency at elevated service temperature (determined by softening point or viscosity test) and durability. Their brittleness at low service temperature (determined by Fraass breaking test) and temperature dependence to consistency (penetration index) may also need to be determined to meet regional requirements for specific conditions, such as extreme cold or wide ambient temperature variations.

To understand the performance of the utilized bitumen, the design of physical properties of the material is highly essential. The standard testing methods are carried out to grade bitumen. Quality assurance of bituminous binders is carried out by penetration test of bitumen and softening point of bitumen, thus with using empirical method.

These empirical tests, however, cannot adequately describe the complicated, rheological behaviour of bituminous binders, which is proved in practice. Bitumen binders have a viscoelastic character. It means that by impact of external forces partially elastic deformation occurs (elastic component) and partially plastic strain occurs (viscosity component). Their behaviour is dependent on the temperature as well as on the size and time duration of the load.

One of the parameter used in rheology to explain the material behaviour is viscosity. Viscosity or glutinousness represents the intrinsic resistance of the material toward the flow caused by external forces, which originates from the chemical and physical interactions of the material itself. Viscosity as the physical property of liquids characterizes flow behaviour and determines flow resistance. In the case of bitumen binders, dynamic viscosity could be used as a qualitative parameter.

\section{Experimental program}

Within laboratory measurements, there were studied the properties of binders for the production of asphalt mixtures which are commonly used in practice for asphalt pavement construction - paving grade bitumen 50/70 and polymer modified bitumen PMB 45/80-75. Tests of basic properties were performed as penetration at $25^{\circ} \mathrm{C}$ according EN 1426, softening point according EN 1427, and dynamic viscosity in the temperature range from 120 to $190{ }^{\circ} \mathrm{C}$. Ten measurements on each type of bitumen of one batch were performed. The results were statistically evaluated and types of bitumen were compared to each other. In addition, penetration, softening, and viscosity measurements on three samples of 50/70 paving grade bitumen and three samples of 35/50 from three different manufacturers were performed to detect differences between samples with aim to identify the differences between the samples, the potential impact of production technology, and the origin of crude oil - raw materials for the production of asphalt. 


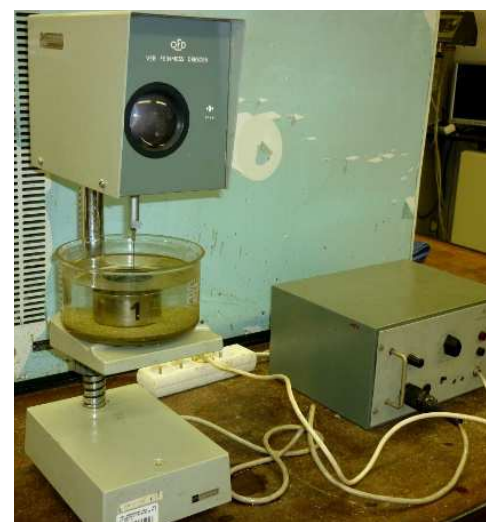

Fig. 0.1: Penetration test of bitumen.

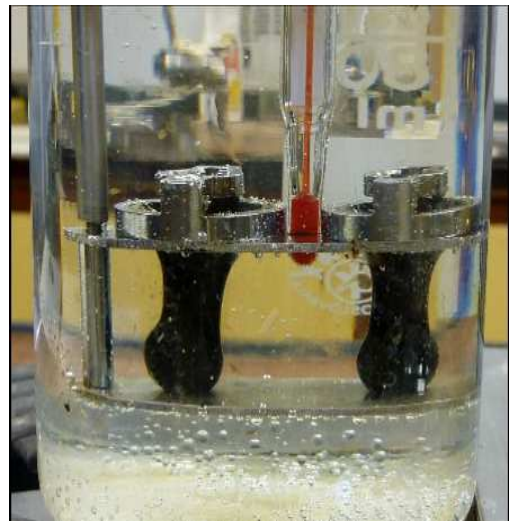

Fig. 0.2: Softening point of bitumen.

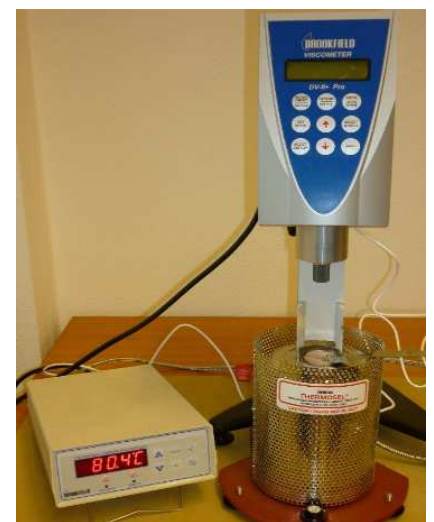

Fig. 0.3: Dynamic viscosity test of bitumen.

\section{Results and analysis}

Most of these methods set the limits to evaluate the test results acceptance. Repeatability of measurements in penetration determination as consistency of bitumen at middle operating temperature $\left(25^{\circ} \mathrm{C}\right.$ ) according to Standard EN 1426 is $4 \%$ of average value (for penetration $\geq 50 \times$ $0.1 \mathrm{~mm}$ ). For the softening point as a characteristic of consistency at an increased operating temperature the repeatability according to EN 1427 for unmodified bitumen is $1{ }^{\circ} \mathrm{C}$ and for polymer modified bitumen the value is $1.5{ }^{\circ} \mathrm{C}$. For viscosity determination according to EN 13302 the repeatability value is $5 \%$.

The values from measurements of softening point and penetration of tested bitumen binders (ten samples of paving grade bitumen 50/70 and ten samples of polymer modified bitumen PMB 45/80-75) from one production batch and statistically evaluated are presented in Table 1.

Table 1: Values from measurements of softening point and penetration of tested bitumen binders.

\begin{tabular}{|c|c|c|c|c|}
\hline \multirow{2}{*}{ Sample } & \multicolumn{2}{|c|}{$\begin{array}{c}\text { Softening point } \\
{\left[{ }^{\circ} \mathbf{C}\right]}\end{array}$} & \multicolumn{2}{c|}{$\begin{array}{c}\text { Penetration } \\
{[\times \mathbf{0 . 1} \mathbf{m m}]}\end{array}$} \\
\cline { 2 - 5 } & $\mathbf{5 0 / 7 0}$ & PMB 45/80-75 & $\mathbf{5 0 / 7 0}$ & PMB 45/80-75 \\
\hline 1. & 48.0 & 80.0 & 60.7 & 59.7 \\
\hline 2. & 48.0 & 77.5 & 62.3 & 61.3 \\
\hline 3. & 49.0 & 82.0 & 62.0 & 61.7 \\
\hline 4. & 48.0 & 79.5 & 61.7 & 56.7 \\
\hline 5. & 48.0 & 80.5 & 61.0 & 55.3 \\
\hline 6. & 48.5 & 79.5 & 61.7 & 60.8 \\
\hline 7. & 48.0 & 78.0 & 60.7 & 60.3 \\
\hline 8. & 49.0 & 82.0 & 62.3 & 61.0 \\
\hline 9. & 48.5 & 79.0 & 61.3 & 54.3 \\
\hline 10. & 48.0 & 80.5 & 62.0 & 54.3 \\
\hline $\bar{x}=\frac{1}{n !} \sum_{i=1}^{n} x_{i}$ & 48.3 & 79.9 & 61.6 & 58.6 \\
\hline$\sigma^{2}=\frac{1}{n} \sum_{i=1}^{n}\left(x_{i}-\bar{x}\right)^{2}$ & 0.16 & 2.00 & 0.36 & 8.26 \\
\hline Mean value & 0.40 & 1.42 & 0.60 & 2.87 \\
\hline Variance & 0.83 & 1.77 & 0.97 & 4.91 \\
\hline Variation coefficient $v[\%]=\frac{\sigma}{\bar{x}} \cdot 100$ & & & \\
\hline
\end{tabular}

During the data analysis [5, 7] the parameters of the file, thus the information about the examined file are acquired. Basic parameters include arithmetic mean, modus, mode (median), which characterize the position (level) of the values and variation range, standard deviation, variation (divergence) which characterize the variability of the values of the analysed parameter. For statistical 
file, the variability of identified values is also characteristic. To express the file variability, the following parameters are used: Variation range $v_{r}$ is only an approximate characteristic of the variability of the values of the tracking character (the difference between the maximum and the minimum value). The variance $\sigma^{2}$ represents the arithmetic mean of the second exponents (squares) of deviations from the mean value $x$. Standard deviation $\sigma$ is a measure that is used to quantify the amount of variation or dispersion of a set of data value. If there are two files, we are often interested whether the values of the examined character are in the first file more dispersed compared to the second file. In the case that both files have the same size, the variability of the character in both files can be compared by their variations and standard deviations, if measurements in both files were made according to the same methodology and roughly equally large averages have been found. Otherwise we will use Pearson's variation coefficient to compare the variability of both sets. We can calculate it as the ratio of the standard deviation and the arithmetic mean. It expresses the degree of variability in percentages of the arithmetic mean.

Fig. 4.1 and 4.2 shows values of standard deviation and variation coefficient of measurements of softening point and penetration of tested bitumen binder.

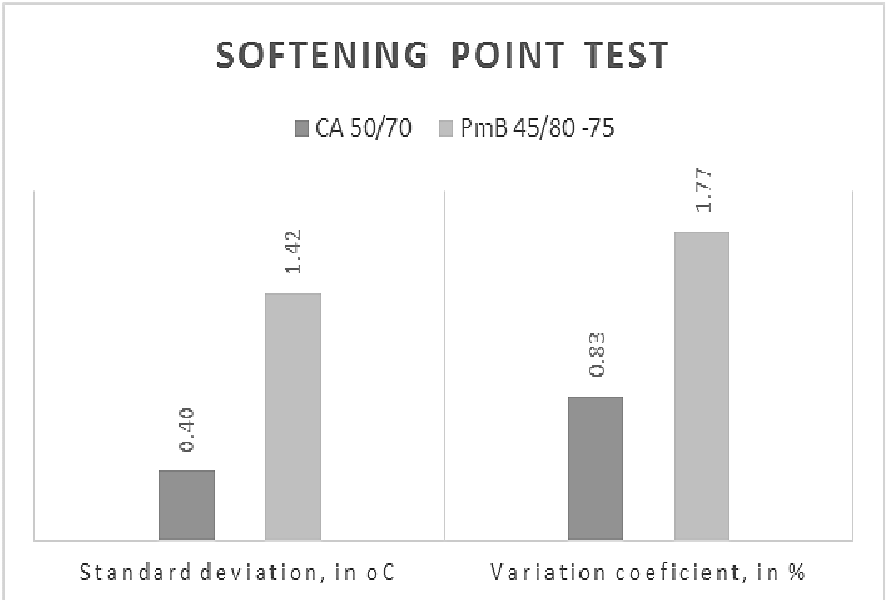

Fig. 0.4: Comparing the standard deviation and the coefficient of variation for the softening point.

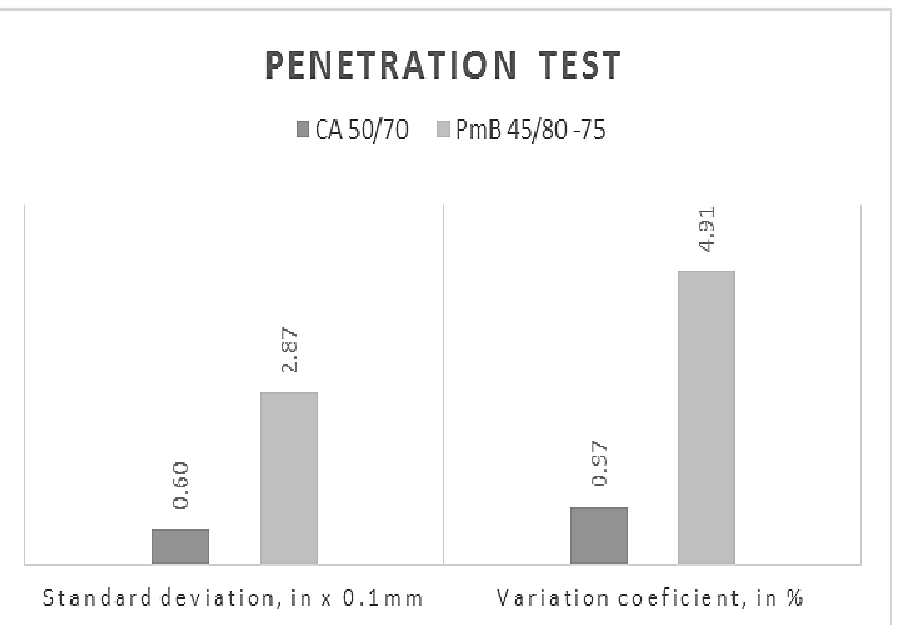

Fig. 0.5: Comparing the standard deviation and the coefficient of variation for penetration test.

The values from measurements of penetration of bitumen samples 50/70 and PMB 45/80-75 are within the prescribed limits, thus from 50 to $70 \times 0.1 \mathrm{~mm}$ for paving grade bitumen and from 45 to $85 \times 0.1 \mathrm{~mm}$ for modified bitumen. Standard deviation and variation coefficient indicate that bigger differences (greater variability) in the results are in the case of modified bitumen.

The softening point defines the upper limit of plasticity, the achievement of which the bitumen passes into the liquid state. The values from measurements of softening point of bitumen samples $50 / 70$ and PMB $45 / 80-75$ are within the prescribed limits, thus from 46 to $54{ }^{\circ} \mathrm{C}$ for paving grade bitumen and more than $75{ }^{\circ} \mathrm{C}$ for modified bitumen. Standard deviation and variation coefficient 
indicate that bigger differences (greater variability) in the results are in the case of modified bitumen. When we compare standard deviation and variation coefficients for softening point with penetration, we can see that in the penetration test, both parameters have higher values - in the case of standard deviation for softening point is the difference between paving grade bitumen and PMB value only $1.02{ }^{\circ} \mathrm{C}$, in the case of penetration it is the difference of $2.27^{\circ} \mathrm{C}$. The coefficient of variation for the softening point is $0.94 \%$, but for the penetration it is $3.94 \%$.

Similarly, the results of the dynamic viscosity measurements in the range from $120{ }^{\circ} \mathrm{C}$ to $190{ }^{\circ} \mathrm{C}$ for both tested bitumens were compared. The results are in Tables 2 and 3. The experimental measurements of dynamic viscosity of bitumen samples were realized by Brookfield viscometer model DV-II+PRO with cylindrical spindle. This rotating spindle viscometer covers a range of shear rates in the range of 1 to $10^{4} \mathrm{~s}^{-1}$ and dynamic viscosity in the range of $10^{-2}$ to $10^{6} \mathrm{~Pa} \cdot \mathrm{s}$ (temperature from $40{ }^{\circ} \mathrm{C}$ to $200{ }^{\circ} \mathrm{C}$ ). For obtained representative results of bituminous binders the viscosity must always be measured at various test temperatures. Typical temperatures for the unmodified or polymer modified bitumen binders are in the range from $90^{\circ} \mathrm{C}$ to $180^{\circ} \mathrm{C}$. For the calculation we use the following relations:

- shear rate at $\mathrm{s}^{-1}$

$S R=R P M . S R C S R$

- shear stress at $\mathrm{N} \cdot \mathrm{cm}^{2}$

SS = TK.SMC.SRC.Torque SS,

- viscosity

$c p=\frac{100}{R P M}$. SMC.TK.Torque,

where: $T K$ is viscometer torque constant (for model RVDV-II+, $T K=1$ ), $R P M$ is current viscometer spindle speed, $S M C$ is current spindle multiplier constant 2 (for torque of model SC4-27, $S M C=25$ ), $S R C$ current spindle shear rate constant (for model SC4-27, $S R C=0.34$ ), Torque is current viscometer torque (\%) expressed as a number between 0 and 100 .

The values from measurements of dynamic viscosity of tested bitumen binders (ten samples of paving grade bitumen 50/70 and ten samples of polymer modified bitumen PMB 45/80-75) from one production batch and statistically evaluated are presented in Table 2 and Table 3.

Table 2: Calculated statistical parameters for dynamic viscosity of paving grade bitumen.

\begin{tabular}{|l|c|c|c|c|c|c|c|c|c|c|c|}
\hline & \multicolumn{8}{|c|}{ Viscosity of CA50/70, in mPa.s at temperature in ${ }^{\circ} \mathbf{C}$} \\
\cline { 2 - 14 } & $\mathbf{1 2 0}$ & $\mathbf{1 3 0}$ & $\mathbf{1 3 5}$ & $\mathbf{1 4 0}$ & $\mathbf{1 5 0}$ & $\mathbf{1 6 0}$ & $\mathbf{1 6 5}$ & $\mathbf{1 7 0}$ & $\mathbf{1 8 0}$ & $\mathbf{1 8 5}$ & $\mathbf{1 9 0}$ \\
\hline Mean value & 4395.4 & 861.2 & 576.3 & 435.9 & 279.2 & 179.2 & 139.3 & 110.4 & 75.9 & 61.6 & 51.6 \\
\hline Variance & 13300.1 & 4052.5 & 1205.9 & 340.0 & 216.0 & 42.5 & 10.4 & 10.1 & 3.8 & 4.7 & 2.4 \\
\hline Standard deviation & 115.3 & 63.6 & 34.7 & 18.4 & 14.7 & 6.5 & 3.2 & 3.2 & 1.9 & 2.2 & 1.5 \\
\hline Variable coefficient, \% & 2.62 & 7.39 & 6.03 & 4.23 & 5.26 & 3.64 & 2.31 & 2.88 & 2.57 & 3.51 & 3.01 \\
\hline
\end{tabular}

Table 3: Calculated statistical parameters for dynamic viscosity of polymer modified bitumen.

\begin{tabular}{|l|c|c|c|c|c|c|c|c|c|c|c|}
\hline & \multicolumn{8}{|c|}{ Viscosity of PMB 45/80-75 in $\mathbf{~ P a \cdot s}$ at temperature in ${ }^{\circ} \mathbf{C}$} \\
\cline { 2 - 13 } & $\mathbf{1 2 0}$ & $\mathbf{1 3 0}$ & $\mathbf{1 3 5}$ & $\mathbf{1 4 0}$ & $\mathbf{1 5 0}$ & $\mathbf{1 6 0}$ & $\mathbf{1 6 5}$ & $\mathbf{1 7 0}$ & $\mathbf{1 8 0}$ & $\mathbf{1 8 5}$ & $\mathbf{1 9 0}$ \\
\hline Mean value & 9869.5 & 3850.5 & 2468.1 & 1661.8 & 1132.5 & 683.8 & 572.8 & 490.2 & 367.7 & 307.4 & 256.7 \\
\hline Variance & 28162.0 & 105204.6 & 36703.8 & 8288.6 & 2307.3 & 599.2 & 719.4 & 213.7 & 343.8 & 20.7 & 50.2 \\
\hline Standard deviation & 167.8 & 324.3 & 191.6 & 91.0 & 48.0 & 24.5 & 26.8 & 14.6 & 18.5 & 4.5 & 7.1 \\
\hline Variable coefficient, \% & 1.70 & 8.42 & 7.76 & 5.48 & 4.24 & 3.58 & 4.68 & 2.98 & 5.04 & 1.48 & 2.76 \\
\hline
\end{tabular}

The results from measurement confirm known fact that modified bitumen has higher values of viscosity at all temperature than unmodified bitumen. 


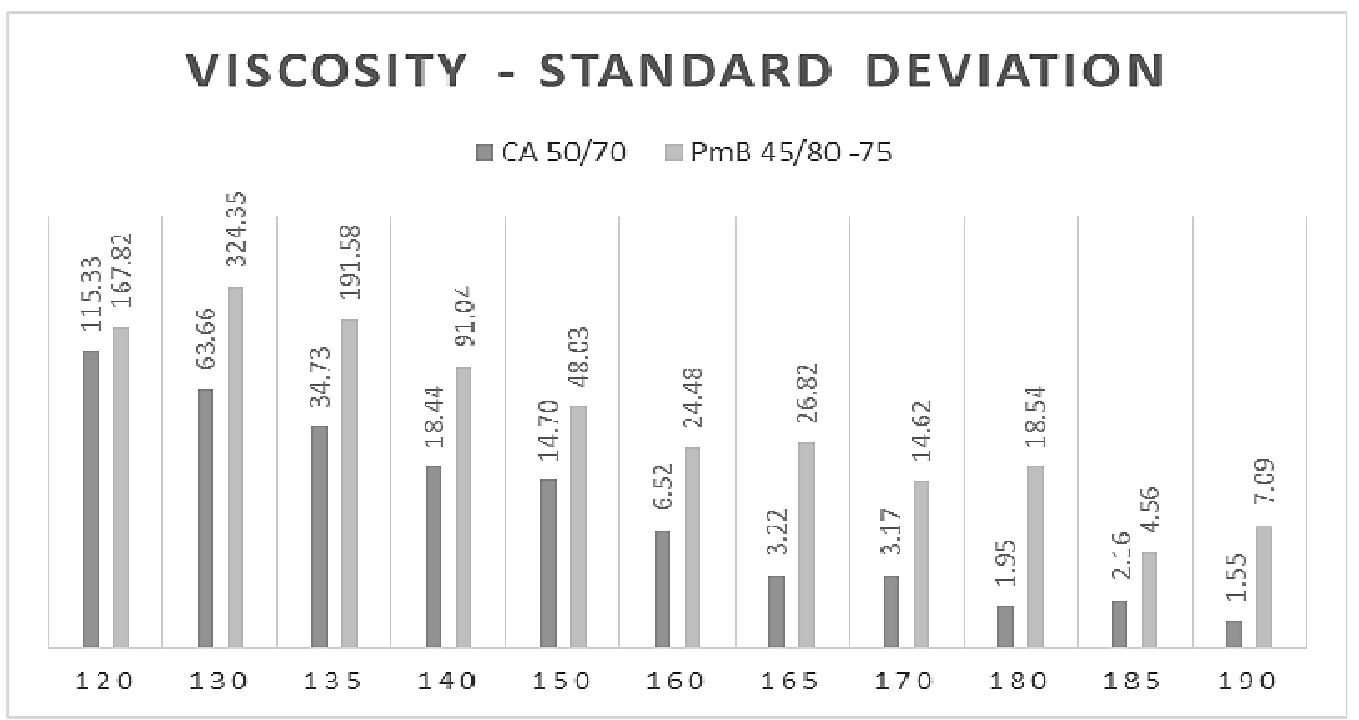

Fig. 0.6: Standard deviation from viscosity measurement.

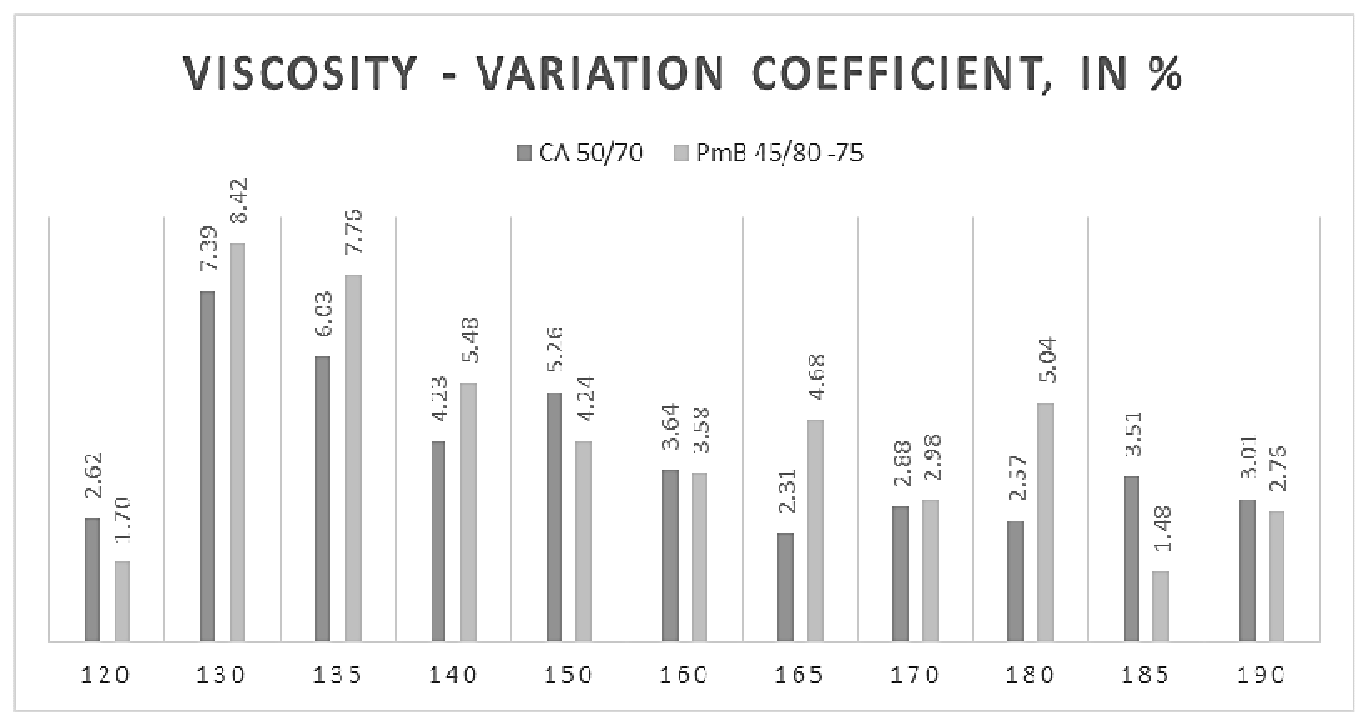

Fig. 0.7: Variation coefficient from viscosity measurement.

Fig. 4.3 shows that paving grade bitumens have smaller values of standard deviation compared to PMB. The highest values of standard deviation can be observed at lower temperatures (120 $140{ }^{\circ} \mathrm{C}$ ), and standard deviation of tested bitumen decreases with increasing temperature (the exception is PMB at temperatures 120,165 , and $180^{\circ} \mathrm{C}$ ). We can also see that paving grade bitumen has a decreasing tendency of values of standard deviation, but PMB bitumen has a decreasing tendency only at lower temperature (from 120 to $160{ }^{\circ} \mathrm{C}$ ). Higher differences of standard deviation between individual binders can be observed at lower temperatures (due to the fact that at lower temperatures the bitumens have higher viscosity values) and with increasing temperature the differences between the binders decrease.

In the case of variation coefficient (Fig. 4.4) we can see that the results are not so clear. At temperatures $120,150,160,185$, and $190{ }^{\circ} \mathrm{C}$, the paving grade bitumen has a higher values of variation range; on the other hand at temperatures $130,135,140,165,170$, and $180{ }^{\circ} \mathrm{C}$, it has a higher values of variation range $\mathrm{PmB}$. We can see the highest values of standard deviation at lower temperatures $\left(120-140^{\circ} \mathrm{C}\right)$ again.

Lower values of the standard deviation and variation coefficient at $120{ }^{\circ} \mathrm{C}$ (as compared to $130{ }^{\circ} \mathrm{C}$ ) may be due to the measurement time (at $120^{\circ} \mathrm{C}$, the spindle is rotated for 180 seconds, and after 180 seconds the viscosity is measured, and at $130^{\circ} \mathrm{C}$ the value of viscosity are measured after 60 seconds). 
In the next steps of the research, there were performed measurements of the dependence between bitumen of the same grade, of different samples from different manufacturers, or from different production batches: 50/70 OMV, 50/70 Orlen, 50/70 MOL and 35/50 OMV, 35/50 Orlen, $35 / 50$ Total. The results from measurement of penetration and softening point are presented in Table 4.

Table 4: Values of softening point and penetration measurements of tested binders: three different samples of bitumen $50 / 70$ and three different samples of bitumen 35/50.

\begin{tabular}{|c|c|c|c|c|}
\hline & \multicolumn{2}{|c|}{$\mathbf{5 0 / 7 0}$} & \multicolumn{2}{|c|}{$\mathbf{3 5 / 5 0}$} \\
\hline SAMPLES & $\begin{array}{c}\text { Softening point, } \\
{ }^{\circ} \mathbf{C}\end{array}$ & $\begin{array}{c}\text { Penetration, } \\
\times \mathbf{0 . 1} \mathbf{m m}\end{array}$ & $\begin{array}{c}\text { Softening point, } \\
{ }^{\circ} \mathbf{C}\end{array}$ & $\begin{array}{c}\text { Penetration, } \\
\mathbf{0} .1 \mathrm{~mm}\end{array}$ \\
\hline 1 & 51.00 & 54.33 & 55.00 & 49.00 \\
\hline 2 & 50.00 & 61.67 & 56.25 & 44.83 \\
\hline 3 & 48.00 & 61.67 & 57.25 & 42.33 \\
\hline Mean value $\bar{x}=\frac{1}{n} \sum_{i=1}^{n} x_{i}$ & 49.66 & 59.22 & 56.16 & 45.38 \\
\hline Variance $\sigma^{2}=\frac{1}{n} \sum_{i=1}^{n}\left(x_{i}-\bar{x}\right)^{2}$ & 1.55 & 11.95 & 0.84 & 7.56 \\
\hline Standard deviation $\sigma=\sqrt{\sigma^{2}}$ & 1.24 & 3.45 & 0.92 & 2.74 \\
\hline Variable coefficient $v[\%]=\frac{\sigma}{\bar{x}}, 100$ & 2.51 & 5.83 & 1.63 & 6.05 \\
\hline
\end{tabular}

A graphical representation of the measurement of the softening point and penetration is presented in Figs. 4.5 and 4.6.

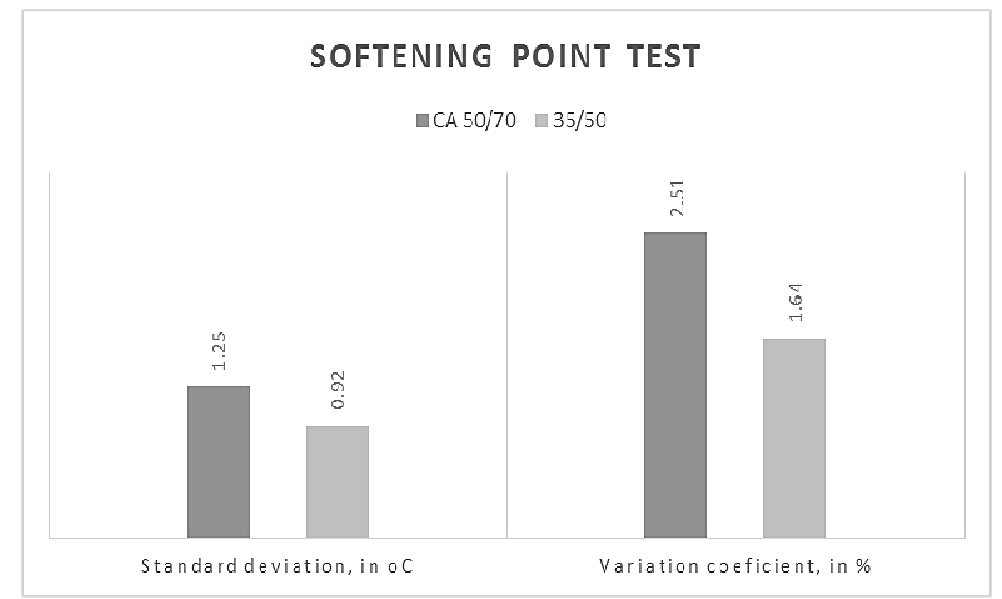

Fig. 4.8: Comparing the standard deviation and the coefficient of variation for the softening point.

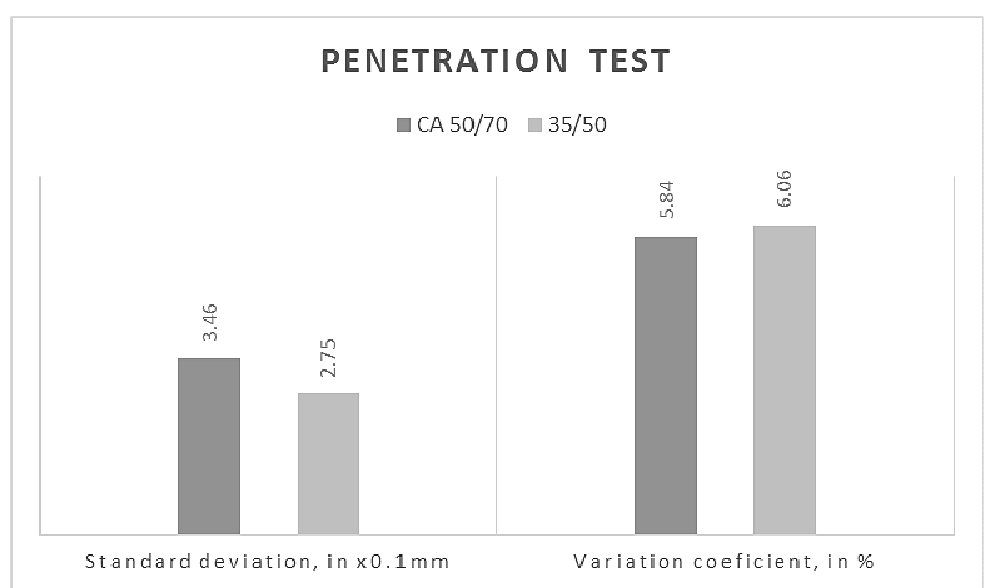

Fig. 4.9: Comparing the standard deviation and the coefficient of variation for penetration. 
Fig. 4.7 shows that paving grade bitumen 50/70 shows higher values of standard deviation and variation coefficient compared to paving grade bitumen $35 / 50$ in the softening point test. Paving grade bitumen 50/70 shows higher values of standard deviation in penetration test, but in case variation coefficient shows higher values $35 / 50$ (Fig. 4.8).

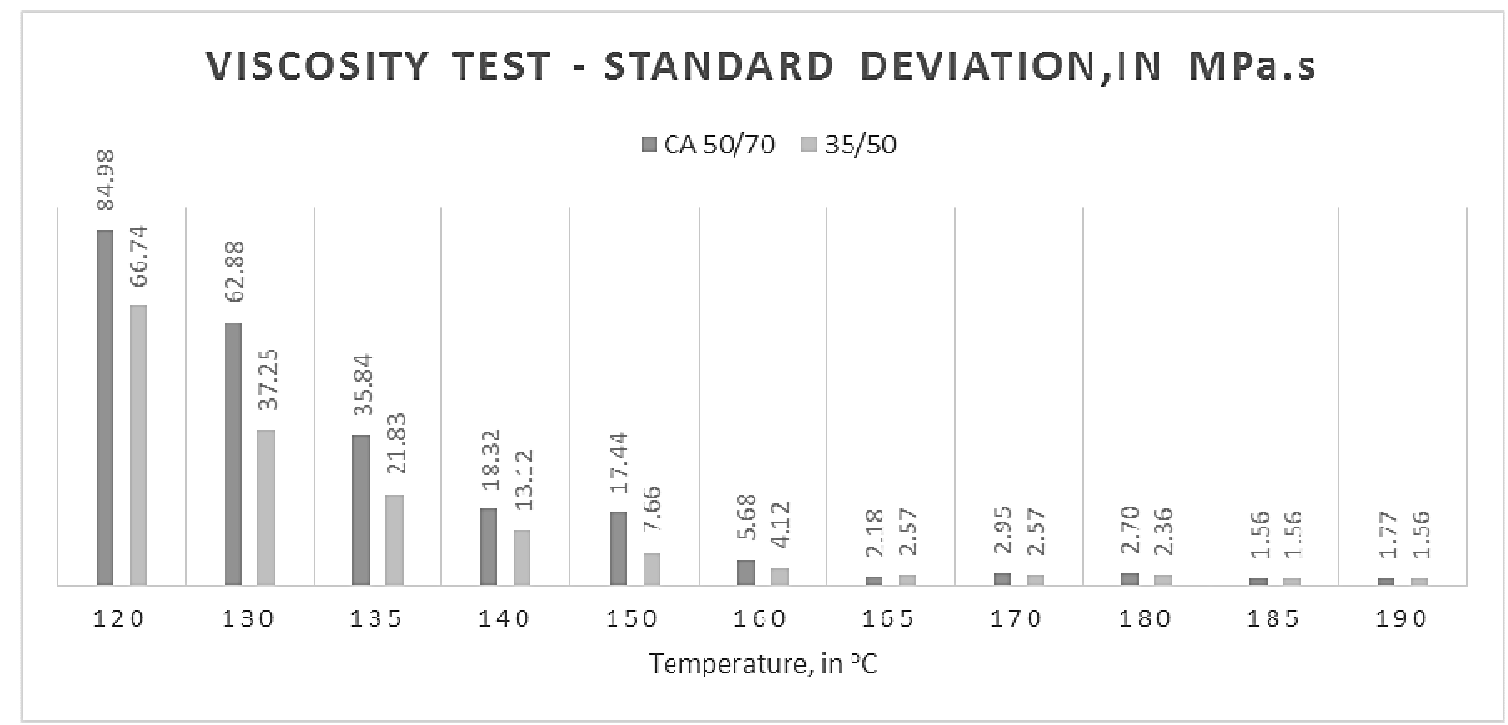

Fig. 0.10: Standard deviation from measurement of viscosity.

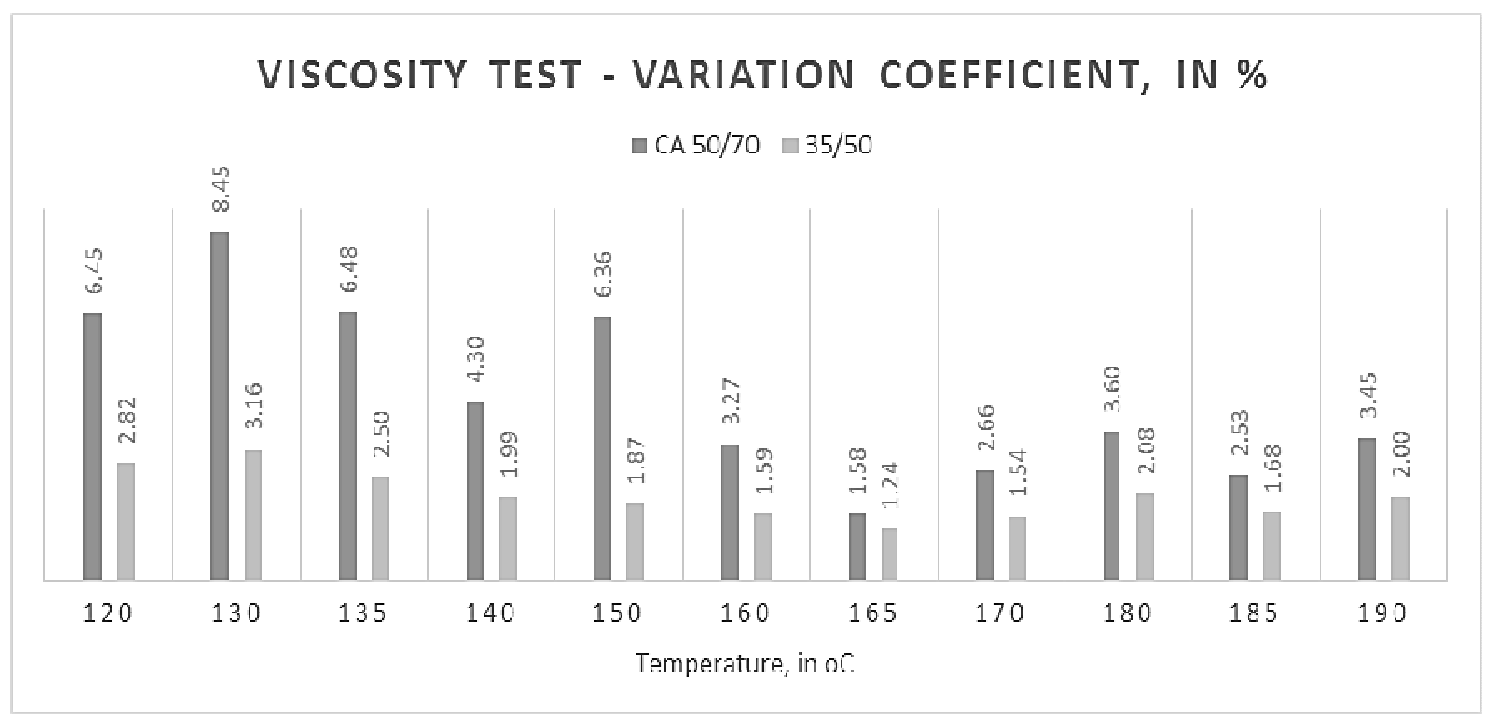

Fig. 0.11: Variation coefficient from measurement of viscosity.

It should be noted that between different types of bitumen from different manufacturers, there are some differences in the measured and achieved test values, but nevertheless all measured results meet the requirements of the data sheets for type of bitumen binder. From the measurements it is also possible to conclude that the greatest differences in measured values were measured for dynamic viscosity and penetration, on the contrary the lowest differences in the results were in the softening point test [4].

\section{Conclusion}

Quality assurance of bituminous binders is carried out by penetration test of bitumen and softening point of bitumen, which represent an empirical approach. These empirical tests, however, cannot adequately describe the complicated, rheological behaviour of bituminous binders, what is also proven by practice. Bitumen binder's behaviour as visco-elastic materials depends on temperature, 
speed, and size of load. One of the parameters characterising this behaviour is viscosity. Measurements confirm known fact that modified bitumen has higher values of viscosity at all temperature than unmodified bitumen. The results show that if we have bitumen (paving grade bitumen and polymer modified bitumen) from one production batch and performed 10 penetration tests and 10 softening point tests, we can see that the results are not the same and therefore the results were evaluated using statistical parameters - standard deviation and variation coefficient. Standard deviation and variation coefficient indicate that bigger differences (greater variability) in the results are in the case of modified bitumen. The results also indicated that when we compare the variability of the results between the individual tests (softening point and penetration), then higher differences of values of standard deviation and of variability coefficient are for the penetration test. Paving grade bitumens have smaller values of standard deviation compared to PMB also for viscosity test. The highest values of standard deviation can be observed at lower temperatures $\left(120-140{ }^{\circ} \mathrm{C}\right)$, and standard deviation of tested bitumen decreases with increasing temperature (the exception is PMB at temperatures 120 , 165 , and $180^{\circ} \mathrm{C}$ ).

Similar variability of results as above can be observed if we performed the tests on bitumen of the same class (batch), but from different manufacturers (50/70 OMV, 50/70 Orlen, 50/70 MOL and $35 / 50$ OMV, 35/50 Orlen, 35/50 Total). The results show that paving grade bitumen 50/70 show higher values of standard deviation and variation coefficient compared to paving grade bitumen $35 / 50$ in the softening point test. In penetration test shows higher values of standard deviation paving grade bitumen 50/70, but in the case of variation coefficient show higher values the $35 / 50$ grade bitumen. In the viscosity test, the 50/70 has a higher standard deviation and a variation coefficient than the 35/50 binder. It could be said that harder bitumen has lower values of standard deviation and variation coefficient in all tests (softening point, penetration, and viscosity).

\section{Acknowledgment}

The research is supported by the project VEGA 1/0300/17 Research of performance related and rheological properties of bituminous binders.

\section{References}

[1] STN EN 1426 Bitumen and bituminous binders. Determination of needle penetration. July 2016.

[2] STN EN 1427 Bitumen and bituminous binders. Determination of the softening point. Ring and Ball method. July 2016.

[3] STN EN 13302 Bitumen and bituminous binders. Determination of dynamic viscosity of bituminous binder using a rotating spindle apparatus. August 2010.

[4] GAJDOŠ, M.: Comparison of properties of bitumen binders from different sources (in Slovak). Bachelor thesis, University of Žilina, 2017.

[5] MARKECHOVÁ, D. - TIRPÁKOVÁ, A. - STEHLÍKOVÁ, B.: The basics of statistics for educators (in Slovak). Nitra, 2011.

[6] COUFALÍK, P.: Rheological properties of bitumen binders (in Czech). Doctoral thesis, Brno university of technology, Brno, 2017.

[7] JUREČKOVÁ, M. - MOLNÁROVÁ, I.: Statistics with excel (in Slovak). Liptovský Mikuláš, 2005.

[8] READ, J. - WHITEOAK, D.: The Shell Bitumen Handbook. $4^{\text {th }}$ edition, Thomas Telford, London, 2003.

[9] ĎURČANSKÁ, D. - DECKÝ, M. - LICBINSKY, R. - HUZLIK, J.: Project SPENS - Sustainable Pavement for European New Member States. Communications - Scientific Letters of the University of Žilina, Vol. 15, Iss. 2, 2013, pp. 49-55.

[10] Data sheets of bitumen binders 1/2010 (in Slovak). September, 2010. 